Digest paper

\title{
Inhibitors of diacylglycerol lipases in neurodegenerative and metabolic disorders
}

\author{
Freek J. Janssen, Mario van der Stelt* \\ Department of Molecular Physiology, Leiden Institute of Chemistry, Leiden University, PO Box 9502, 2300 RA Leiden, Netherlands
}

\section{A R T I C L E I N F O}

\section{Article history:}

Received 2 June 2016

Revised 22 June 2016

Accepted 26 June 2016

Available online 27 June 2016

\section{Keywords:}

Diacylglycerol lipases

2-Arachidonoylglycerol

Neurodegenerative diseases

Neuroinflammation

Obesity

Metabolic syndrome

Drug development

\begin{abstract}
A B S T R A C T
2-Arachidonoylglycerol (2-AG) is an endocannabinoid that activates the cannabinoid receptors type 1 and 2. It also serves as an important lipid precursor for the eicosanoid signaling pathway. Consequently, 2-AG is involved in many physiological functions, including anxiety, food intake, inflammation, memory, pain sensation and neurotransmission. Diacylglycerol lipases (DAGLs) are the main biosynthetic enzymes for 2-AG and their role in several pathophysiological conditions is currently under investigation. In this Digest we review all DAGL inhibitors reported to date and their effects in preclinical models of neurodegeneration and metabolic disorders.
\end{abstract}

(c) 2016 Elsevier Ltd. All rights reserved.
2-Arachidonoylglycerol (2-AG) is an important endogenous signaling lipid. 2-AG activates the cannabinoid receptors type 1 and 2 (CB1R and CB2R) and is, therefore, termed an endocannabinoid. ${ }^{1-3}$ Multiple lipid species can activate the CBRs, but 2-AG, together with anandamide, is the most well studied endocannabinoid. 2AG contributes to CB1R mediated synaptic plasticity and acts as a retrograde messenger inhibiting GABAergic and glutamatergic neurotransmission. ${ }^{4,5}$ The CBRs are involved in many physiological functions, including food intake, ${ }^{6-8}$ inflammation, ${ }^{9,10}$ memory formation, ${ }^{11-13}$ mood, ${ }^{14,15}$ locomotor acivity, ${ }^{16,17}$ pain sensation, ${ }^{18}$ addiction and reward. ${ }^{19}$ The exact contribution of 2-AG to these physiological processes remains poorly understood. The levels of 2-AG are tightly regulated in the central nervous system, because it is produced on demand and rapidly degraded by specialized enzymes. ${ }^{20-22}$ Phospholipase C- $\beta$ (PLC $\beta$ ) catalyses the formation of diacylglycerols from cell membrane phospholipid phosphatidylinositol-4,5-bisphosphate $\left(\mathrm{PIP}_{2}\right)$. Diacylglycerols are subsequently converted by sn-1 specific diacylglycerol lipases $\alpha$ and $\beta$ (DAGLs) to monoacylglycerols, including 2-AG. ${ }^{20}$ DAGLs belong

\footnotetext{
Abbreviations: 2-AG, 2-arachidonoylglycerol; ABPP, activity-based protein profiling; ABHD6 and ABHD12, $\alpha / \beta$-hydrolase domain proteins 6 and 12; CB1R and $\mathrm{CB} 2 \mathrm{R}$, cannabinoid receptors type 1 and 2; DAGLs, sn-1 specific diacylglycerol lipases $\alpha$ and $\beta$; FAAH, fatty acid amide hydrolase; MAGL, monoacylglycerol lipase.

* Corresponding author. Tel.: +31 715274768 .

E-mail address: m.van.der.stelt@chem.leidenuniv.nl (M. van der Stelt).
}

to the large family of serine hydrolases, having a typical $\alpha / \beta$ hydrolase fold and Ser-His-Asp catalytic triad. The two DAGL isoforms $(\alpha$ and $\beta$ ) share extensive homology and differ mostly in a large C-terminal tail, which is present in DAGL $\alpha$, but not in DAGL $\beta .^{20}$ Genetic disruption of DAGL $\alpha$ in mice resulted in a strong reduction of 2-AG levels in the brain (80-90\%), whereas in DAGL $\beta^{-1-}$ mice the 2 -AG level was approximately $50 \%$ reduced in the brain. ${ }^{4,5} 2$-AG is mainly metabolized by monoacylglycerol lipase (MAGL) and to a lesser extent by $\alpha / \beta$-hydrolase domain proteins 6 and 12 (ABHD6 and ABHD12). This leads to the production of arachidonic acid (AA). ${ }^{22}$ Both 2-AG and AA may serve as substrates for oxidative enzymes (cyclooxygenases) yielding pro-inflammatory prostaglandins and their ester derivatives, respectively (Fig. 1). ${ }^{23}$ Inhibitors of MAGL have contributed to the understanding of the physiological role of 2-AG (see for recent reviews ${ }^{24-26}$ ) and are currently tested in preclinical models and clinical trials for neurodegenerative diseases. Here, we will review the current state of the art of the diacylglycerol lipases inhibitors and discuss their potential in metabolic disorders and neurodegeneration.

Assays to measure DAGL activity: Several DAGL activity assays are currently available. The first class of assays employs surrogate substrates, i.e., para-nitrophenylbutyrate, 6,8-difluoro-4-methylumbelliferyl (DiMFU) octanoate and EnzChek ${ }^{\circledR}$, and is generally used for inhibitor identification. ${ }^{28-31}$ The main advantage is that product formation can be monitored real-time, generally by absorption or fluorescence measurement. The cost-effectiveness 


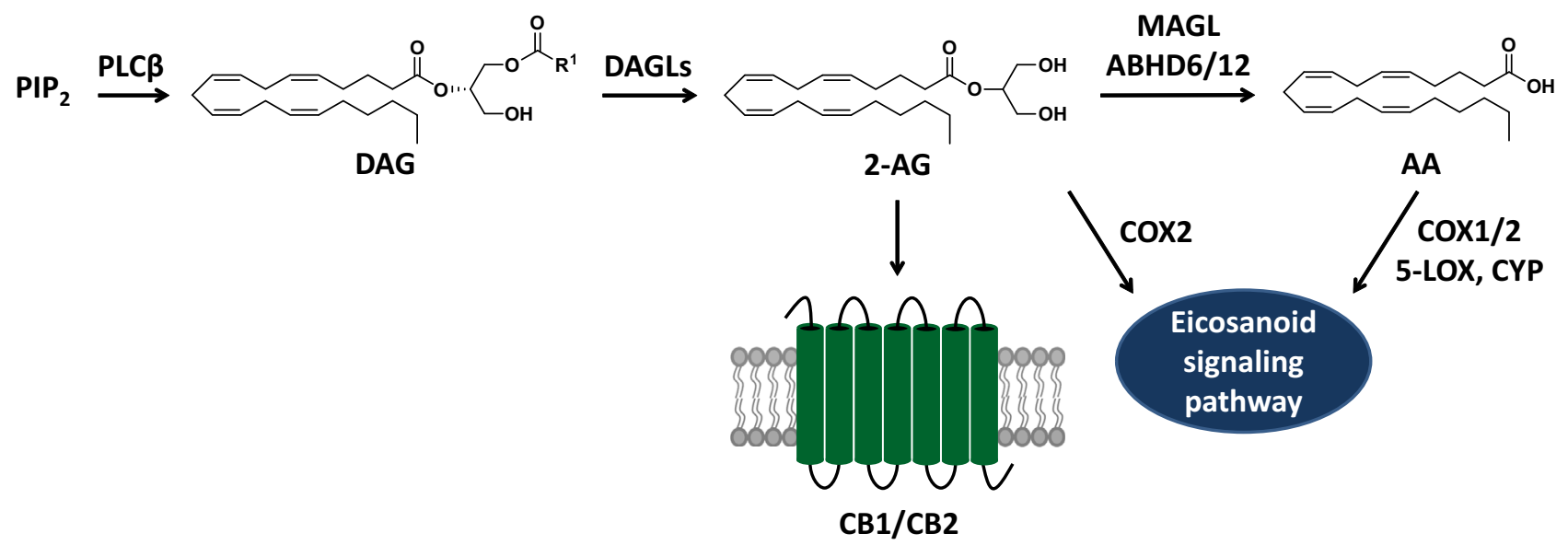

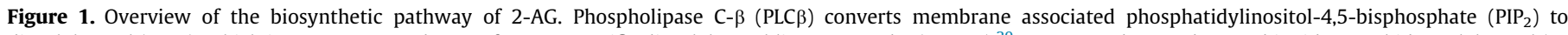

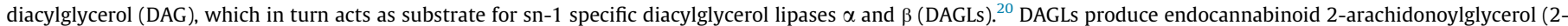

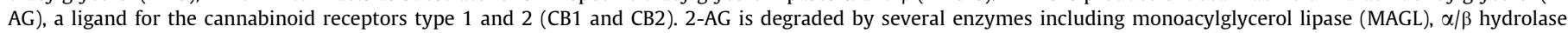

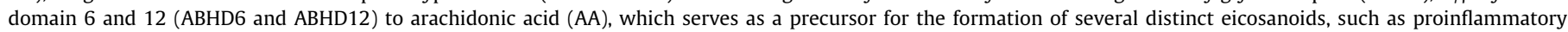

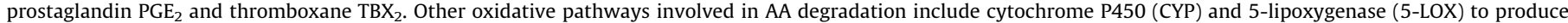
epoxyeicosanoids and leukotrienes, respectively, while direct oxidation of 2-AG by COX2 may result in the formation of prostaglandin-esters. ${ }^{23,27}$

and easy detection of surrogate substrates/products make these assays valuable tools for high-throughput screening applications. ${ }^{28,30,32}$ However, surrogate substrates generally have attenuated binding affinities for the enzyme compared to DAGLs' natural substrate $s n$-1-stearoyl-2-arachidonoyl-glycerol. This may affect inhibitor potencies $\left(\mathrm{IC}_{50}\right.$ ) obtained with these assays. Consequently, the use of the natural substrate is preferred for further inhibitor profiling.

The second class of assays makes use of a natural substrate of DAGLs. Radiometric assays have been used to measure DAGL $\alpha$ activity in vitro, utilizing radiolabeled diacylglycerol, such as sn1-stearoyl-2- $\left[{ }^{14} \mathrm{C}\right]$ arachidonoylglycerol, as a substrate. ${ }^{20}$ This method is highly sensitive, but requires lipid extraction, fractionation on thin layer chromatography and quantification of radiolabeled $2-\left[{ }^{14} \mathrm{C}\right]$ arachidonoylglycerol via scintillation counting, thereby making this assay labor-intensive. Of note, the radioactive substrate it is not commercially available. This restricts the widespread use of the radiometric assay. Alternatively, liquid chromatographic (LC) methods coupled to mass spectrometry (MS), have been employed to measure direct 2-AG formation. ${ }^{33}$ Although, LC/MS methods avoid the use of radiolabeled substrates and are highly accurate, it does require lipid extraction and separation of phases. Consequently, only limited number of samples can be measured. Both radiometric and LC/MS-based assays prohibit monitoring of reaction progress in real-time due to their discontinuous setup. Therefore, a third method was recently developed, in which the conversion of the natural substrate 1-stearoyl-2-arachidonoylsn-glycerol (SAG) was coupled to the formation of a fluorescent dye employing a five enzyme cascade. ${ }^{34}$ Extraction or fractionation steps were not necessary allowing SAG hydrolysis to be studied in real time in 96-well plate format using recombinant DAGL $\alpha$ or DAGL $\beta$ as well as mouse brain membrane fractions. ${ }^{34,35}$

Finally, the third class of assays employs activity-based protein profiling (ABPP). ABPP is a chemical biological technique that allows the rapid and efficient visualization of endogenous serine hydrolase activity in complex, native samples without the need of having substrate assays. ${ }^{36,37}$ Typically, ABPP is used in a competitive setting, where a pool of enzymes is treated with an inhibitor, followed by a broad spectrum or tailored activity-based probe (ABP) that labels all residual serine hydrolase activity. The ABP reporter tag allows for identification and quantification of inhibitor off-targets that are shared by the probe, using either in-gel fluorescence scanning or mass spectrometry. As such, ABPP measures activity and selectivity of irreversible and reversible inhibitors in cells and tissue lysates, ${ }^{38}$ making it a highly valuable and complementary method next to classical substrate assays. Three different tailored ABPs have been developed for the detection of DAGL activity in proteomes: HT-01, ${ }^{33}$ MB064 ${ }^{39}$ and DH379. ${ }^{35}$

DAGL inhibitor classes: To date, six different chemotypes have been reported as DAGL inhibitors, which can be classified into (a) reversible inhibitors: $\alpha$-ketoheterocycles and glycine sulfonamides, and (b) irreversible inhibitors: bis-oximino-carbamates, $\beta$-lactones, fluorophosphonates and 1,2,3-triazole ureas.

$\alpha$-Ketoheterocycles: Using an ABPP-screen with the tailored activity-based probe MB064 and a pharmacophore model, Baggelaar et al. identified the $\alpha$-ketoheterocycle LEI104 (Fig. 2) as the first reversible inhibitor for DAGL $\alpha$. LEI104 was, however, weakly active in a cellular assay and not selective over FAAH, the enzyme responsible for the metabolism of the other endocannabinoid anandamide (Table 1$)^{39}$ The structure activity relationships (SAR) of the $\alpha$-ketoheterocycles were investigated by screening a focussed library of 1040 compounds. The $\alpha$-keto group functioned as an electrophilic warhead and its reactivity could be tuned by selection of appropriate substituents on the scaffold. The $4 \mathrm{~N}$-oxazolopyridine heterocycle proved to be the most optimal scaffold and compounds with a C6-C9 methylene phenyl acyl substituent were the most potent inhibitors. ${ }^{32}$ Using this extensive SAR, a DAGL $\alpha$ homology model was validated and applied to the design of LEI105, a $p$-tolyl derivative of LEI104 (Fig. 2). ${ }^{40}$ Competitive and comparative chemoproteomics revealed that LEI105 was a highly potent and selective, covalent reversible inhibitor of DAGL $\alpha$ and DAGL $\beta$, which did not target other proteins in the endocannabinoid system, including CB1R and CB2R, ABHD6, ABHD12, MAGL and FAAH (Table 1). LEI105 dose-dependently reduced 2AG levels in neuronal cells without affecting anandamide levels. Finally, LEI105 attenuated synaptic plasticity by blocking depolarization-induced suppression of inhibition (DSI) in CA1 pyramidal neurons in mouse hippocampal slices. LEI105 has not been tested in in vivo models yet.

Glycine sulfonamides: The glycine sulfonamides were reported by Appiah et al. as the first non-covalent reversible inhibitors of DAGL. ${ }^{28}$ Their high throughput screening campaign identified compound 1 as a DAGL $\alpha$ inhibitor, which was selective over MAGL and pancreatic lipase (Fig. 2, Table 1). Interestingly, the glycine 


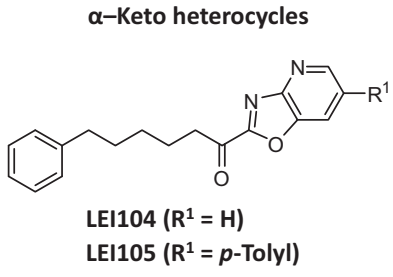

LEI104 $\left(R^{1}=H\right)$
LEI105 $\left(R^{1}=p\right.$-Tolyl $)$

\section{Glycine sulfonamides}<smiles>CCOC(=O)c1ccc(CN(CC(=O)O)S(=O)(=O)c2ccc3c(c2)CCC(C)(C)O3)cc1</smiles>

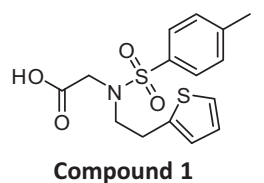

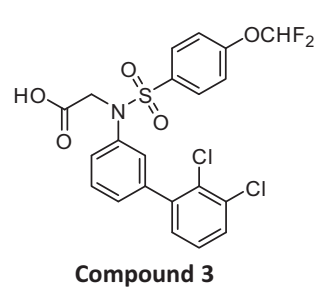

Compound 3

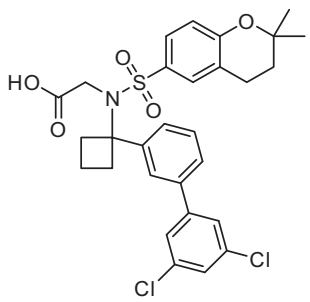

Compound 24
Bis-oximino-carbamates<smiles>O=C(NCCCCCCNC(=O)ON=C1CCCCC1)ON=C1CCCCC1</smiles>

RHC80267

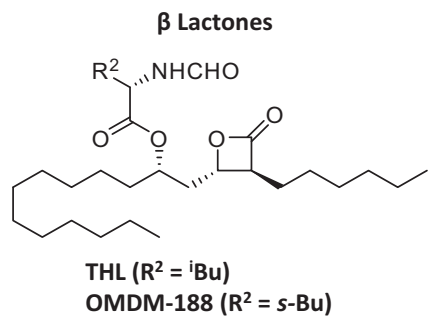

Fluorophosphonates

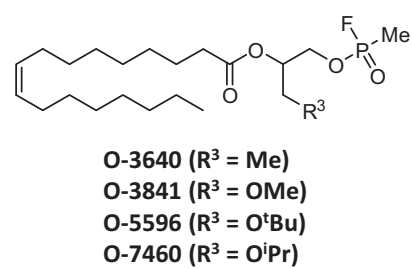

$1,2,3$ Triazole ureas
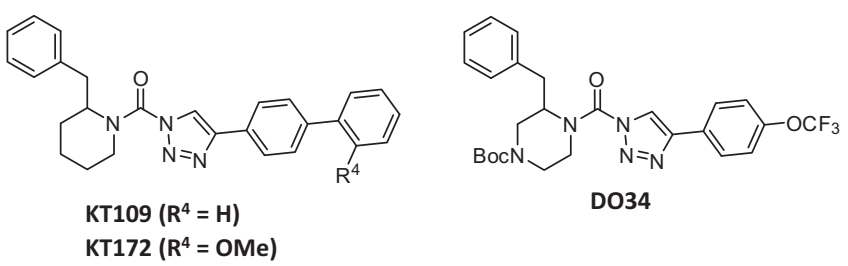

KT172 $\left(R^{4}=\right.$ OMe $)$

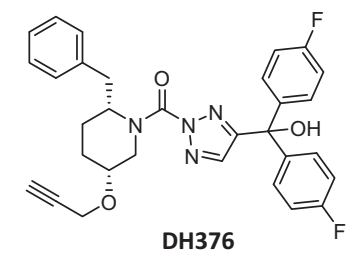

DH376

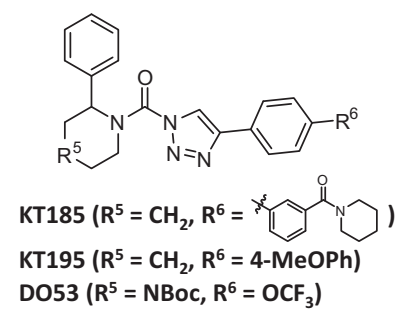

Figure 2. Current DAGL chemotypes and their corresponding inhibitors. ${ }^{20,28,33,35,41,43,48,55,56,58}$

sulfonamides lack an obvious warhead that can covalently interact with the catalytically active serine in the enzyme. SAR studies revealed that the sulfonamide was required for proper positioning of the side groups, probably due to its characteristic perpendicular angle, and the carboxylate was essential for activity. ${ }^{41}$ Based on the initial hit compound 1, and patent literature, ${ }^{42}$ LEI106 (Fig. 2) was identified as a DAGL inhibitor with nanomolar potency. ABPP revealed LEI106 to be selective over MAGL, but ABHD6 and two additional unknown off-targets were inhibited (Table 1). Docking of LEI106 in a DAGL $\alpha$ homology model suggested that the carboxylate interacted with an intricate hydrogen bonding network of the catalytic triad. Recently, Chupak et al. published a full account of their extensive optimization of the glycine sulfonamides, which resulted in the identification of compounds $\mathbf{3}$ and $\mathbf{2 4}$ (Fig. 2, Table 1). ${ }^{43}$ They found that glycine sulfonamide $\mathbf{3}$ is a cellular active and orally bio-available DAGL $\alpha / \beta$ inhibitor. Due to potential toxicity issues associated with biphenyl-amines, compound $\mathbf{3}$ was further optimized to compound 24. The latter compound was a peripherally restricted, highly potent and dual DAGL $\alpha / \beta$ inhibitor with some minor affinity for the human ether-a-go-go channel $\left(\mathrm{IC}_{50}=40 \mu \mathrm{M}\right)$ and a good pharmacokinetic profile. ${ }^{43}$ No additional functional or in vivo efficacy data have been reported with this series to date.

Bis-oximino-carbamates: RHC80267 (Fig. 2) was one of the first DAGL inhibitors reported in the literature, but it is only weakly active on DAGL $\alpha$ and not selective. RHC80267 inhibited at least 7 others targets, including fatty acid amide hydrolase (FAAH) and lipoprotein lipase (LPL, see Table 1). ${ }^{39,44}$ This activity and selectivity profile makes it less suitable to study the biological role of DAGLs.

$\beta$-Lactones: Tetrahydrolipstatin (THL, Orlistat, Fig. 2) is a peripherally restricted, FDA approved anti-obesity drug (Xenigal ${ }^{\circledR}$, Alli ${ }^{\circledR}$ ) that inhibits gastric and pancreatic lipases, which are essential for fat processing in the gastrointestinal track. ${ }^{45-47}$ Since the discovery of THL as a potent DAGL inhibitor, ${ }^{20} \beta$-lactones have been extensively investigated as DAGL inhibitors with a focus on changing the amino acid substituent on the chiral $\delta$ hydroxyl moiety. ${ }^{48,49}$ THL inhibited DAGL $\alpha$ and DAGL $\beta$ with nanomolar potency in natural substrate assays to a similar extent (Table 1). OMDM-188, a $N$-formyl-L-isoleucine derivative of THL (Fig. 2), demonstrated improved selectivity over FAAH and MAGL, but micromolar antagonistic activity on the CB1R $\left(K_{\mathrm{i}}=6 \mu \mathrm{M}\right.$, Table 1). This may complicate the interpretation of results obtained with this compound, if the in vitro studies are carried out at high inhibitor concentration $(>10 \mu \mathrm{M}) .{ }^{48}$ OMDM-188 has been used to investigate whether $2-A G$ is released 'on demand' or from preformed pools during neuronal activity. While some studies with THL and OMDM-188 show that acute DAGL inhibition attenuates DSI in hippocampal CA1 pyramidal cells, ${ }^{50,51}$ other studies with the same inhibitors found no such effect. ${ }^{52}$ The discrepancy between the various electrophysiological studies could be potentially attributed to differences in tissue penetration of the compounds, due to their relatively high lipophilicity, ${ }^{50}$ but off-targets effects cannot be ruled out either. Recent studies using novel DAGL inhibitors, such as LEI $105^{40}$ and 1,2,3-triazole ureas, ${ }^{35}$ have confirmed that CB1R-mediated synaptic plasticity is dependent on acute DAGL activity, which supports the hypothesis of 'on demand' production of 2-AG.

Recently, OMDM-188 has been used to study the biological role of DAGL $\alpha$ in gastrointestinal motility. Bashashati et al. showed that DAGL $\alpha$ is expressed throughout the enteric nervous system and its inhibition by OMDM-188 reversed slowed gastrointestinal motility, intestinal contractility and constipation through a CB1R dependent mechanism. ${ }^{53}$ Conversely, inhibition of MAGL prolonged the whole gut transit time. ${ }^{54}$ These studies suggest that DAGL $\alpha$ is a potential target for the treatment of constipation. 2-AG levels in the ileum or colon of the genetically constipated mice were, however, not significantly affected and the effect of OMDM-188 on 
Table 1

Overview of known DAGL inhibitors per assaytype and chemotype, values are $\mathrm{pIC}_{50}$

\begin{tabular}{|c|c|c|c|c|c|}
\hline Chemotype & Compound & Surrogate substrate assay & Natural substrate assay & ABPP assay & Identified off-targets \\
\hline Bis-oximino-carbamates & RHC80267 & $\begin{array}{l}5.3(\alpha)^{\mathrm{i}} \\
4.6(\alpha)^{\mathrm{ii}}\end{array}$ & - & - & $\begin{array}{l}\text { ABHD6 }{ }^{44} \\
\text { FAAH } \\
\text { LPL }\end{array}$ \\
\hline \multirow[t]{2}{*}{$\beta$-Lactones } & THL & $\begin{array}{l}9.6(\alpha)^{\mathrm{i}} \\
9.4(\alpha)^{\mathrm{ii}} \\
7.6(\beta)^{\mathrm{iii}}\end{array}$ & $\begin{array}{l}8.4(\alpha)^{\mathrm{iv}} \\
7.2(\alpha)^{\mathrm{v}} \\
7.0(\beta)^{\mathrm{v}} \\
6.0(\alpha)^{\mathrm{vi}}\end{array}$ & $\begin{array}{l}6.6(\alpha)^{\mathrm{vii}} \\
5.7(\beta)^{\mathrm{vii}}\end{array}$ & $\begin{array}{l}\text { ABHD6 }{ }^{39,44,48} \\
\text { ABHD12 } \\
\text { ABHD16A } \\
\text { DDHD2 } \\
\text { LyPLA } \\
\text { CB1 }\end{array}$ \\
\hline & OMDM-188 & $8.2(\beta)^{\mathrm{iii}}$ & $7.8(\alpha)^{\mathrm{vi}}$ & - & CB1 (minor) ${ }^{48}$ \\
\hline Fluoro phosphonates & $0-3640$ & - & $6.3(\alpha)^{\mathrm{vi}}$ & - & $\begin{array}{l}\text { TAGL }^{55} \\
\text { FAAH } \\
\text { MAGL (minor) } \\
\text { CB1 (minor) }\end{array}$ \\
\hline & $\begin{array}{l}0-3841 \\
0-5596 \\
0-7460\end{array}$ & $\begin{array}{l}- \\
- \\
-\end{array}$ & $\begin{array}{l}6.8(\alpha)^{\mathrm{vi}} \\
7.0(\alpha)^{\mathrm{vi}} \\
6.2(\alpha)^{\mathrm{vi}}\end{array}$ & $\begin{array}{l}- \\
- \\
-\end{array}$ & $\begin{array}{l}\text { None reported }^{55} \\
\text { None reported }^{56} \\
\text { KIAA } 1363^{58}\end{array}$ \\
\hline \multirow[t]{3}{*}{ 1,2,3-Triazole ureas } & $\begin{array}{l}\text { KT109 } \\
\text { KT172 }\end{array}$ & - & $\begin{array}{l}7.6(\alpha)^{\text {iv }} \\
7.1(\beta)^{\text {viii }} \\
7.1(\beta)^{\text {viii }}\end{array}$ & $\begin{array}{l}5.6(\alpha)^{\mathrm{vii}} \\
7.4(\beta)^{\mathrm{vii}} \\
6.9(\alpha)^{\mathrm{vii}} \\
7.2(\beta)^{\mathrm{vii}}\end{array}$ & $\begin{array}{l}\text { ABHD6 }^{33} \\
\text { PLA2G7 } \\
\text { ABHD6 6 } \\
\text { MAGL (minor) } \\
\text { PLA2G7 (minor) }\end{array}$ \\
\hline & DH376 & - & $\begin{array}{l}8.2(\alpha)^{\mathrm{vi}} \\
8.6(\beta)^{\mathrm{ix}}\end{array}$ & $\begin{array}{l}8.9(\alpha)^{\mathrm{vii}} \\
8.3(\beta)^{\mathrm{vii}}\end{array}$ & $\begin{array}{l}\text { ABHD6 } 6^{35} \\
\text { CES1C } \\
\text { LIPE } \\
\text { BCHE }\end{array}$ \\
\hline & DO34 & - & $\begin{array}{l}8.2(\alpha)^{\mathrm{vi}} \\
8.1(\beta)^{\mathrm{ix}}\end{array}$ & $\begin{array}{l}9.3(\alpha)^{\mathrm{vii}} \\
8.6(\beta)^{\mathrm{vii}}\end{array}$ & $\begin{array}{l}\text { ABHD6 }^{35} \\
\text { CES1C } \\
\text { PLA2G7 } \\
\text { PAFAH2 } \\
\text { ABHD2 }\end{array}$ \\
\hline$\alpha$-Keto heterocycles & $\begin{array}{l}\text { LEI104 } \\
\text { LEI105 }\end{array}$ & $\begin{array}{l}7.4(\alpha)^{x} \\
8.5(\alpha)^{x}\end{array}$ & $\begin{array}{l}6.3(\alpha)^{\mathrm{vi}} \\
6.6(\alpha)^{\mathrm{vi}} \\
7.9(\alpha)^{\mathrm{xi}}\end{array}$ & $\begin{array}{l}6.3(\alpha)^{\mathrm{xi}} \\
7.6(\alpha)^{\mathrm{xi}}\end{array}$ & $\begin{array}{l}\text { FAAH }^{40,64} \\
\text { None reported } \\
\text { (FAAH selective) }\end{array}$ \\
\hline \multirow[t]{3}{*}{ Glycine sulfonamides } & $\begin{array}{l}1 \\
3\end{array}$ & $\begin{array}{l}6.3(\alpha)^{\mathrm{xii}} \\
8.6(\alpha)^{\mathrm{xii}} \\
7.4(\beta)^{\mathrm{xii}}\end{array}$ & $\begin{array}{l}- \\
-\end{array}$ & $\begin{array}{l}- \\
-\end{array}$ & $\begin{array}{l}\text { None reported } \\
\text { None reported }\end{array}$ \\
\hline & 24 & $\begin{array}{l}9.2(\alpha)^{\mathrm{xii}} \\
7.4(\beta)^{\mathrm{xii}}\end{array}$ & - & - & hERG (minor) $)^{43}$ \\
\hline & LEI106 & $7.7(\alpha)^{x}$ & $\begin{array}{l}6.0(\alpha)^{\mathrm{iv}} \\
6.2(\alpha)^{\mathrm{vi}}\end{array}$ & $6.9(\alpha)^{\mathrm{xi}}$ & $\begin{array}{l}\text { ABHD6 }{ }^{41} \\
\text { Two unknown }\end{array}$ \\
\hline
\end{tabular}

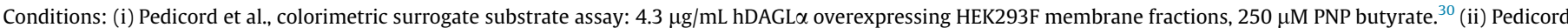

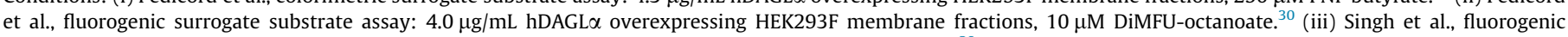

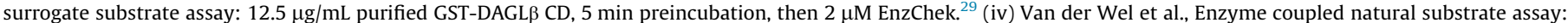

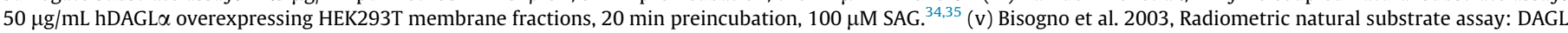

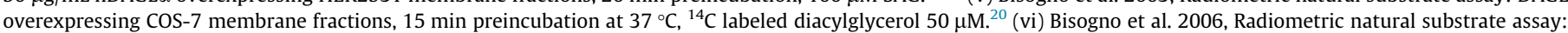

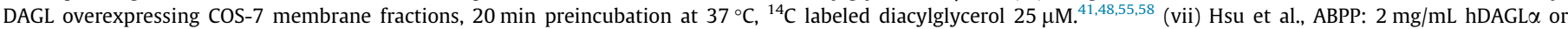

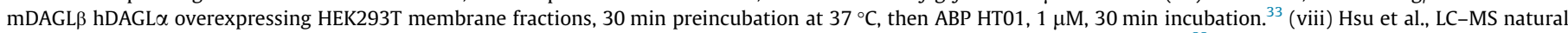

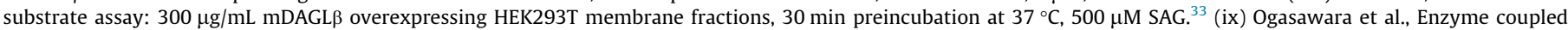

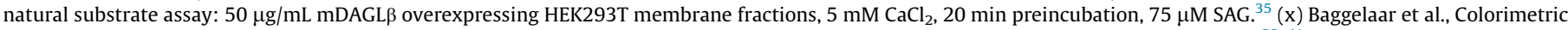

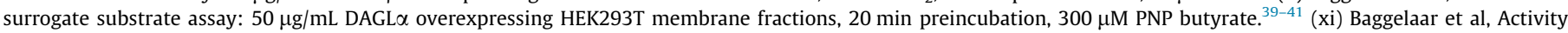

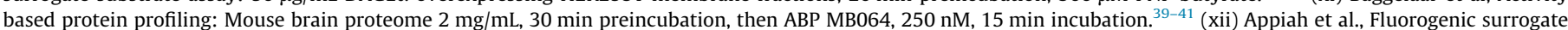
substrate assay: $12.0 \mu \mathrm{g} / \mathrm{mL}$ DAGL $\alpha$ overexpressing membranes, $10 \mu \mathrm{M}$ DiMFU-octanoate. ${ }^{28,43}$

pancreatic and gastrointestinal lipase is currently unknown. Further studies may address these questions.

Fluorophosphonates: 0-3640, 0-3841 and 0-5596 covalently inhibit DAGL and are mimetics of the endogenous lipid 2-oleoylglycerol carrying a fluorophosphonate group as a warhead (Fig. 2). ${ }^{55,56}$ These compounds have nanomolar potency in a natural substrate assay and, in particular 0-3841 and 0-5596 show few off-target activities (Table 1). ${ }^{55,56}$ O-3640 and 0-3841 have, however, little to no effect in a cellular assay in which ionomycin is used to stimulate the formation of 2-AG in N18TG2 cells. The lack of cellular activity is perhaps due to chemical instability of the inhibitors or low cell membrane permeability. ${ }^{55,56}$ Remarkably, 0-3841 was neuroprotective in a malonate model of Huntington's disease. ${ }^{57}$ 0-3841 prevented the formation of prostaglandin E2 glyceryl ester that exerted neurotoxicity, whereas MAGL-inhibitors exacerbated neuronal damage. Optimization of the substituent at the $s n-3$ position of $0-3841$ led to the identification of $0-7460$ (Fig. 2), which was moderately active on human DAGL $\alpha$ $\left(\mathrm{IC}_{50}=690 \mathrm{nM}\right)$ and reduced 2-AG levels in situ. Neutral cholesterol ester hydrolase 1 (KIAA1363) was detected with ABPP as an important off-target. 0-5596 and 0-7460 decreased the amount of palatable food ingested by mice in a dose-dependent manner and slightly reduced body weight. ${ }^{56,58}$ These observations are in line with the results obtained with DAGL $\alpha$ KO mice (see below). ${ }^{59}$

1,2,3-Triazole ureas: DAGL inhibitors based on the 1,2,3-triazole urea scaffold have been instrumental to determine the physiological role of DAGLs in macrophages and brain. Hsu et al. developed the first DAGL $\beta$ inhibitors that were active in an in vivo model of inflammation. ${ }^{33}$ KT109 and KT172 (Fig. 2), but not KT195, a control compound, reduced the levels of 2-AG, AA and eicosanoids 
(thromboxane A2, leukotriene B4, prostaglandin D2 and E2) in peritoneal macrophages of lipopolysaccharide (LPS)-treated mice. ${ }^{33}$ Moreover, KT109 and KT172 significantly decreased proinflammatory cytokine tumor necrosis factor $\alpha$ (TNF $\alpha$ ) in LPS-treated mice. This demonstrated that DAGL $\beta$ plays a pivotal role in the regulation of macrophage inflammatory response in vivo. Of note, KT109 does inhibit DAGL $\alpha$ (Table 1 ) and depending on its concentration and time of incubation, DAGL $\alpha$ may be fully inhibited. KT109 and KT172 do not act in the central nervous system, presumably, because they are not able to cross the blood-brain barrier. Wilkerson et al. investigated the effect of DAGL $\beta$ inhibition on inflammatory and neuropathic pain. ${ }^{60}$ Local inhibition of DAGL $\beta$ by KT109 at the site of inflammation reduced LPS-induced allodynia in mice, whereas general i.c.v. or i.t administration was ineffective. This suggests that peripheral inhibition of DAGL $\beta$ may represent a novel avenue to treat pathological pain. ${ }^{60}$

To investigate the biological role of DAGLs in the brain, Ogasawara et al. developed the triazole ureas DH376 and DO34 (Fig. 2). DH376 and DO34 were highly potent and selective DAGL inhibitors. ${ }^{35}$ ABPP experiments demonstrated a limited off-target profile for DH376 and DO34 in the brain and designated DO53 as a paired control compound. Both DAGL inhibitors, but not DO53, fully blocked GABAergic (DSI) and glutamatergic (DSE) neurotransmission in hippocampal and cerebellar slices, respectively. Acute blockade of DAGL in mice produced a striking reorganization of bioactive lipid networks, including elevations of DAGs and reductions in endocannabinoids and eicosanoids. For example, doseand time-dependent reductions in 2-AG, AA and $\mathrm{PGE}_{2}$ levels were observed in the brain of mice treated i.p. with D034 or DH376, but not with D053. Importantly, the in vivo half-life of DAGL $\alpha$ was short (2-4 h) and accompanied by ongoing DAGL $\alpha$ protein production in the brain that generated a strong, tonic flux of 2AG. It was suggested that modulation of DAGL $\alpha$ half-life may thus provide neurons with a mechanism to influence the magnitude and duration of 2-AG signaling and associated physiological processes, such as learning and memory. ${ }^{35}$ of note, anandamide levels were also affected by DAGL inhibition by DH376 and DO34 and not by control compound D053. The molecular mechanism underlying this in vivo cross-talk between the two endocannabinoids is not clear at the moment, but was also observed in DAGL KO animals. ${ }^{4,5,61}$ DAGL inhibition by DH376 and D034 reduced the formation of 2-AG, AA and proinflammatory prostaglandins as well as pro-inflammatory cytokine IL1 $\beta$ upon LPS-treatment in mice. ${ }^{35}$ DAGL inhibition also attenuated LPS-induced anapyrexia (reduction of core body temperature), which is contrast to enhanced anapyrexia mediated by acute blockade of MAGL. ${ }^{62}$ This suggests that 2-AG has an important role in the regulation of body temperature during neuroinflammation. Viader et al. demonstrated by combined genetic and pharmacological evaluation that disruption of either DAGL $\alpha$ or DAGL $\beta$ contributes to lower the neuroinflammatory response in vivo. ${ }^{75}$ They found that DAGL $\beta$ is key in regulating $2-A G$ levels in microglia and that LPS treated DAGL $\beta^{-1-}$ mice show attenuated microglial activation without changes in overall 2-AG and prostaglandin levels in brain.

Buczynski et al. showed that inhibition of DAGL by KT172 (Fig. 2), but not control compound KT185, restores GABAergic signaling at dopaminergic neurons in the ventral tegmental area (VTA), which is lost during chronic nicotine exposure. ${ }^{63}$ Accordingly, rats treated with KT172 significantly less self-administered nicotine without affecting other operant response or locomotion. This may indicate that the 2-AG signaling, mediated by DAGL $\alpha$, is involved in the regulation of reward and addiction.

Therapeutic potential of DAGL inhibitors in anti-obesity and neuroprotection: The endocannabinoid system is a clinically proven signaling pathway controlling the energy balance in humans. In fact, the first generation CB1R antagonist/inverse agonist
Rimonabant was considered one of the most promising therapeutic drugs to treat human obesity, until the appearance of central psychiatric side effects resulted in its removal from the market in $2008{ }^{65-67}$ Rimonabant reduced food intake, body weight and waist circumference in obese patients and improves cardiovascular risk factors. ${ }^{65,66,68}$ Currently, several lines of evidence suggest that 2$A G$, and not anandamide (nor constitutively active CB1Rs), regulates CB1R-dependent food intake. 2-AG levels are increased in the hypothalamus of fasting mice ${ }^{7}$ and pharmacological intervention using 0-5596 and 0-7460 leads to reduced food intake in mice. ${ }^{58}$ Third, DAGL $\alpha^{-1-}$ mice showed hypophagia and leanness similar to that of $\mathrm{CB}^{-1-}$ mice, while knockout mice of DAGL $\beta$ and $N$-acyl phosphatidylethanolamine phospholipase D (NAPEPLD, the main enzyme responsible for anandamide synthesis) did not share this phenotype. ${ }^{59,61}$ Interestingly, DAGL $\alpha$ knockout mice had also low fasting insulin, triglyceride, and total cholesterol levels, and after glucose challenge had normal glucose but very low insulin levels. ${ }^{59}$ Taken together, these data suggest that selective interference with DAGL $\alpha$ signaling may represent a novel therapeutic avenue to treat obesity and the metabolic syndrome.

Inflammatory processes are associated with obesity and with many neurodegenerative diseases, including stroke, Parkinson's and Alzheimer's disease. ${ }^{69}$ Prostaglandins produced by cyclooxygenases from arachidonic acid (AA) are important pro-inflammatory stimuli. Cyclooxygenase inhibitors show neuroprotection in animal models of Parkinson's and Alzheimer's disease, but their gastrointestinal and cardiovascular actions have limited their use in humans. ${ }^{70}$ Nomura et al. discovered that MAGL regulates AA levels in specific tissues, which is required for prostaglandin synthesis by cyclooxygenases type 1 and 2 (COX1 and COX2). ${ }^{71}$ For instance, MAGL is the predominant enzyme producing AA in the brain, liver and lung, whereas phospholipase $\mathrm{A} 2\left(\mathrm{PLA}_{2}\right)$ regulates AA levels in the gut and spleen. Inhibition of MAGL activity in LPS-treated mice resulted in an attenuated neuroinflammatory response as witnessed by a marked decrease in pro-inflammatory prostaglandins and cytokine formation in the brain. MAGL inhibitors improved neurological outcome in animal models of Multiple Sclerosis, ${ }^{72}$ Parkinson's ${ }^{71,73}$ and Alzheimer disease, ${ }^{24}$ thereby providing proof-of-principle for therapeutic intervention using this biochemical pathway in various models of neuroinflammation and neurodegeneration. Of note, CB1R activation by elevated 2-AG levels did not seem to be involved in the protective response. Concomitant chronic activation of the CB1R by elevated 2-AG levels has previously been shown to lead to adaptations of the endocannabinoid system (e.g., down regulation of CB1R and physical dependence). ${ }^{74}$ It is currently unknown how elevated 2-AG levels will impact CB1R-mediated signaling under chronic neurodegenerative conditions. Therefore, DAGL inhibition may provide an alternative approach to reduce AA formation in the brain without accumulation of 2-AG and (chronic) CB1R activation. The first studies with $1,2,3$ triazole ureas DH376 and DO34 have demonstrated that DAGLs regulate the formation of proinflammatory prostaglandins and cytokines under neuroinflammatory conditions. ${ }^{35}$ The efficacy of DAGL inhibitors in mouse models of Multiple Sclerosis, Parkinson's and Alzheimer's diseases have, however, not been reported yet. Of note, in a malonate model of Huntington's disease DAGL inhibitors conferred neuroprotection, whereas MAGL inhibitors exacerbated neuronal damage. ${ }^{27,57}$ Oxidative metabolism of 2-AG was suggested to result in the formation of toxic metabolites. ${ }^{57}$ In conclusion, it will be important to determine the efficacy and therapeutic window of both MAGL and DAGL inhibitors in parallel with respect to CB1R mediated adverse effects and activation of alternative metabolic pathways.

Potential adverse side effects of DAGL inhibitors: Suppression of CB1R signaling with antagonists such as Rimonabant, is linked to neuropsychiatric side effects, including anxiety and depression. ${ }^{76}$ 
The exact contribution of DAGLs in the regulation of emotion has been studied with DAGL $\alpha$ knockout mice. These studies indicate that 2-AG signaling is also important for the regulation of neuropsychiatric behavior. ${ }^{61,59,77}$ For example, Jenniches et al. reported that DAGL $\alpha^{-1-}$ mice display significantly reduced maternal care, increased anxiety in light/dark box and open field tests, reduced fear extinction and increased behavioral despair. ${ }^{61}$ Powell et al. noted similarities in behavioral phenotypes of $\mathrm{CB} 1^{-1-}$ mice and DAGL $\alpha^{-1-}$ in the hot plate, marble burying, open-field rearing, forced swim and open-field distance traveled tests, which were different from their wild type counter parts. Importantly, there were some phenotypic differences between the CB1 and DAGL $\alpha$ knockout mice. In particular, DAGL $\alpha$ knockout mice demonstrated anxiolytic responses in platform tests and in the open field test, which were not observed with $\mathrm{CB} 1^{-1-}$ mice. ${ }^{59}$ Shoneshy et al. noted increased anxiety in both male and female DAGL $\alpha^{-1-}$ mice, while only female mice displayed increased anhedonia. ${ }^{77}$ Several studies indicate that perturbation of DAGL $\alpha$ activity, surprisingly, also decreased anandamide levels. ${ }^{4,5,35,61}$ The consequences of this in vivo cross-talk between the two biosynthetic pathways in relation to potential neuropsychiatric behavior is not known to date. Interestingly, partial restoration of 2-AG levels in $\mathrm{DAGL}^{-1-}$ mice by treatment of a MAGL inhibitor normalized the anxiety-related behavior. ${ }^{77}$ DAGL inhibitors that produce a graded, dose-dependent blockade of 2-AG production in the CNS, such as DH376 and D034, may, therefore, provide an excellent opportunity to test whether a therapeutic window can be established. In addition, selective DAGL $\beta$ inhibitors could be of therapeutic importance since disruption of DAGL $\beta$ activity has been shown to attenuate neuroinflammatory response in vivo without affecting synaptic transmission. $^{75}$

Box 1. Important questions regarding DAGL inhibitors in metabolic and neurological disorders

\section{General}

-Can we develop truly subtype-selective (peripherally restricted) DAGL inhibitors?

-Does chronic DAGL inhibition alter $\mathrm{CB}$ receptor sensitivity?

-Does pharmacological DAGL inhibition induce anxiety, stress and fear responses?

-Can a therapeutic window be established using (reversible) DAGL inhibitors?

-Can we uncouple anandamide and 2-AG biosynthesis using DAGL inhibitors?

\section{Metabolic disorders}

-Can centrally active selective DAGL $\alpha$ inhibitors reduce food seeking behavior and induce weight loss, without inducing neuropsychiatric side effects?

-Can peripherally restricted DAGL inhibitors induce weight loss, improve cardiovascular risk factors and decrease insulin resistance?

\section{Neurological disorders}

-Can selective DAGL inhibitors reduce negative reward associated behavior and contribute to the treatment of drug abuse (e.g alcohol or opioids)?

-What is the specific role 2-AG signaling during neuroinflammation (i.e. DAGL versus MAGL inhibition)? -Are DAGL inhibitors effective in models of neurodegenerative disease (Alzheimer's and Parkinson's disease, MS, etc.)?
To conclude, the development of DAGL knockout mice in combination with in vivo active DAGL inhibitors have greatly contributed to the understanding of the physiological role of DAGLs. Recent findings suggest that DAGL inhibition may be beneficial in the treatment of metabolic disorders, such as obesity, diabetes and metabolic syndrome, as well as neuroinflammation, addiction and pathological pain. Exciting times lay ahead as several drug discovery efforts to further optimize DAGLs inhibitors are ongoing. Several important questions still need to be addressed (See Box 1). For example, can we develop orally, bioavailable, subtype selective and centrally active DAGL inhibitors? In addition, peripheral restricted subtype selective inhibitors would also be of interest. This would complete the set of chemical tools required to elucidate the specific roles of DAGL $\alpha$ and $\beta$ in the various tissues. From a therapeutic point of view, the establishment of a therapeutic window over the untoward neurological outcomes could perhaps best be achieved with reversible, selective DAGL inhibitors.

\section{Acknowledgement}

This work was supported by the The Netherlands Organisation for Scientific Research (NWO-CW ECHO grant to M.S.).

\section{References and notes}

1. Sugiura, T.; Kondo, S.; Sukagawa, A.; Nakane, S.; Shinoda, A.; Itoh, K. Yamashita, A.; Waku, K. Biochem. Biophys. Res. Commun. 1995, 215, 89.

2. Mechoulam, R.; Ben-Shabat, S.; Hanus, L.; Ligumsky, M.; Kaminski, N. E; Schatz, A. R.; Gopher, A.; Almog, S.; Martin, B. R.; Compton, D. R.; Pertwee, R. G.; Griffin, G.; Bayewitch, M.; Barg, J.; Vogel, Z. Biochem. Pharmacol. 1995, 50, 83.

3. Stella, N.; Schweitzer, P.; Piomelli, D. Nature 1997, 388, 773.

4. Tanimura, A.; Yamazaki, M.; Hashimotodani, Y.; Uchigashima, M.; Kawata, S.; Abe, M.; Kita, Y.; Hashimoto, K.; Shimizu, T.; Watanabe, M.; Sakimura, K.; Kano, M. Neuron 2010, 65, 320.

5. Gao, Y.; Vasilyev, D. V.; Goncalves, M. B.; Howell, F. V.; Hobbs, C.; Reisenberg M.; Shen, R.; Zhang, M.-Y. M.-Y.; Strassle, B. W.; Lu, P.; Mark, L.; Piesla, M. J.; Deng, K.; Kouranova, E. V.; Ring, R. H.; Whiteside, G. T.; Bates, B.; Walsh, F. S.; Williams, G.; Pangalos, M. N.; Samad, T. A.; Doherty, P. J. Neurosci. 2010, 30, 2017.

6. Colombo, G.; Agabio, R.; Diaz, G.; Lobina, C.; Reali, R.; Gessa, G. L. Life Sci. 1998, $63,113$.

7. Di Marzo, V.; Goparaju, S. K.; Wang, L.; Liu, J.; Bátkai, S.; Járai, Z.; Fezza, F.; Miura, G. I.; Palmiter, R. D.; Sugiura, T.; Kunos, G. Nature 2001, 410, 822.

8. Koch, M.; Varela, L.; Kim, J. D. J. G.; Kim, J. D. J. G.; Hernández-Nuño, F.; Simonds, S. E.; Castorena, C. M.; Vianna, C. R.; Elmquist, J. K.; Morozov, Y. M. Rakic, P.; Bechmann, I.; Cowley, M. A.; Szigeti-Buck, K.; Dietrich, M. O.; Gao, X.B.; Diano, S.; Horvath, T. L. Nature 2015, 519, 45.

9. Rajesh, Mohanraj; Pan, Hao; Mukhopadhyay, Partha; Sándor, Bátkai; OseiHyiaman, Douglas; Haskó, György; Liaudet, Lucas; Gao, Bin; Pacher, P. J. Leukoc. Biol. 2007, 82, 1382.

10. Rajesh, M.; Mukhopadhyay, P.; Sándor, B.; Haskó, G.; Liaudet, L.; Huffman, J. W.; Csiszar, A.; Ungvari, Z.; Mackie, K.; Chatterjee, S.; Pacher, P. Am. J. Physiol. 2007, 141, 520.

11. Reibaud, M.; Obinu, M. C.; Ledent, C.; Parmentier, M.; Böhme, G. A.; Imperato, A. Eur. J. Pharmacol. 1999, 379, R1.

12. Hampson, R. E.; Deadwyler, S. A. Neurobiol. Dis. 1998, 5, 474.

13. Marsicano, G.; Wotjak, C. T.; Azad, S. C.; Bisogno, T.; Rammes, G.; Cascio, M. G.; Hermann, H.; Tang, J.; Hofmann, C.; Zieglgänsberger, W.; Di Marzo, V.; Lutz, B. Nature 2002, 418, 530.

14. Navarro, M.; Hernandez, E.; Munoz, R. M.; del Arco, I.; Villanua, M. A.; Carrera, M. R.; Rodriguez de Fonseca, F. Neuroreport 1997, 8, 491.

15. Haller, J.; Bakos, N.; Szirmay, M.; Ledent, C.; Freund, T. F. Eur. J. Neurosci. 2002, $16,1395$.

16. Dewey, W. L. Pharmacol. Rev. 1986, 38, 151.

17. Zimmer, A.; Zimmer, A. M.; Hohmann, A. G.; Herkenham, M.; Bonner, T. I. Proc Natl. Acad. Sci. U.S.A. 1999, 96, 5780.

18. Calignano, A.; La Rana, G.; Giuffrida, A.; Piomelli, D. Nature 1998, 394, 277.

19. Ledent, C.; Valverde, O.; Cossu, G.; Petitet, F.; Aubert, J.-F.; Beslot, F.; Bohme, G. A.; Imperato, A.; Pedrazzini, T.; Roques, B. P.; Vassart, G.; Fratta, W.; Parmentier, M. Science 1999, 283, 401.

20. Bisogno, T.; Howell, F.; Williams, G.; Minassi, A.; Cascio, M. G.; Ligresti, A.; Matias, I.; Schiano-Moriello, A.; Paul, P.; Williams, E. J.; Gangadbaran, U.; Hobbs, C.; Di Marzo, V.; Doherty, P. J. Cell Biol. 2003, 163, 463.

21. Dinh, T. P.; Carpenter, D.; Leslie, F. M.; Freund, T. F.; Katona, I.; Sensi, S. L.; Kathuria, S.; Piomelli, D. Proc. Natl. Acad. Sci. U.S.A. 2002, 99, 10819.

22. Blankman, J. L.; Simon, G. M.; Cravatt, B. F. Chem. Biol. 2007, 14, 1347.

23. Rouzer, C. A.; Marnett, L. J. Chem. Rev. 2011, 111, 5899. 
24. Chen, R.; Zhang, J.; Wu, Y.; Wang, D.; Feng, G.; Tang, Y. P.; Teng, Z.; Chen, C. Cell Rep. 2012, 2, 1329.

25. Kohnz, R. A.; Nomura, D. K. Chem. Soc. Rev. 2014, 43, 6859.

26. Mulvihill, M. M.; Nomura, D. K. Life Sci. 2013, 92, 492.

27. Kozak, K. R.: Rowlinson, S. W.: Marnett, L. J. J. Biol. Chem. 2000, 275, 33744.

28. Appiah, K. K.; Blat, Y.; Robertson, B. J.; Pearce, B. C.; Pedicord, D. L.; Gentles, R. G.; Yu, X. C.; Mseeh, F.; Nguyen, N.; Swaffield, J. C.; Harden, D. G.; Westphal, R. S.; Banks, M. N.; O’Connell, J. C. J. Biomol. Screen. 2014, 19, 595.

29. Singh, P. K.; Markwick, R.; Lu, L.; Howell, F. V.; Williams, G.; Doherty, P. Biochemistry 2016, 55, 2713.

30. Pedicord, D. L.; Flynn, M. J.; Fanslau, C.; Miranda, M.; Hunihan, L.; Robertson, B J.; Pearce, B. C.; Yu, X. C.; Westphal, R. S.; Blat, Y. Biochem. Biophys. Res. Commun. 2011, 411, 809 .

31. Singh, P. K.; Markwick, R.; Howell, F. V.; Williams, G.; Doherty, P. Biosci. Rep. 2016, 1.

32. Janssen, F. J.; Baggelaar, M. P.; Hummel, J. J. A.; Overkleeft, H. S.; Cravatt, B. F.; Boger, D. L.; Van Der Stelt, M. J. Med. Chem. 2015, 58, 9742.

33. Hsu, K. L.; Tsuboi, K.; Adibekian, A.; Pugh, H.; Masuda, K.; Cravatt, B. F. Nat. Chem. Biol. 2012, 8, 999.

34. Van Der Wel, T.; Janssen, F. J.; Baggelaar, M. P.; Deng, H.; Den Dulk, H.; Overkleeft, H. S.; Van Der Stelt, M. J. Lipid Res. 2015, 56, 927.

35. Ogasawara, D.; Deng, H.; Viader, A.; Baggelaar, M. P.; Breman, A.; den Dulk, H.; van den Nieuwendijk, A. M. C. H.; Soethoudt, M.; van der Wel, T.; Zhou, J.; Overkleeft, H. S.; Sanchez-Alavez, M.; Mo, S.; Nguyen, W.; Conti, B.; Liu, X.; Chen, Y.; Liu, Q.; Cravatt, B. F.; van der Stelt, M. Proc. Natl. Acad. Sci. U.S.A. 2015, 113.

36. Liu, Y.; Patricelli, M. P.; Cravatt, B. F. Proc. Natl. Acad. Sci. U.S.A. 1999, 96, 14694

37. Kidd, D.; Liu, Y.; Cravatt, B. F. Biochemistry 2001, 40, 4005.

38. Leung, D.; Hardouin, C.; Boger, D. L.; Cravatt, B. F. Nat. Biotechnol. 2003, 21, 687.

39. Baggelaar, M. P.; Janssen, F. J.; Vanesbroeck, A. C. M.; Dendulk, H.; Allara, M.; Hoogendoorn, S.; McGuire, R.; Florea, B. I.; Meeuwenoord, N.; Vandenelst, H. Vandermarel, G. A.; Brouwer, J.; Dimarzo, V.; Overkleeft, H. S.; Vanderstelt, M. Angew. Chem., Int. Ed. 2013, 52, 12081.

40. Baggelaar, M. P.; Chameau, P. J. P.; Kantae, V.; Hummel, J.; Hsu, K.-L.; Janssen, F.; Van Der Wel, T.; Soethoudt, M.; Deng, H.; Den Dulk, H.; Allarà, M.; Florea, B. I.; Di Marzo, V.; Wadman, W. J.; Kruse, C. G.; Overkleeft, H. S.; Hankemeier, T.; Werkman, T. R.; Cravatt, B. F.; Van Der Stelt, M. J. Am. Chem. Soc. 2015, 137, 8851

41. Janssen, F. J.; Deng, H.; Baggelaar, M. P.; Allarà, M.; Van Der Wel, T.; Den Dulk, H.; Ligresti, A.; Van Esbroeck, A. C. M.; McGuire, R.; Di Marzo, V.; Overkleeft, H. S.; Van Der Stelt, M. J. Med. Chem. 2014, 57, 6610.

42. Chupak, L. S.; Zheng, X.; Ding, M.; Hu, S.; Huang, Y.; Gentles, R.; G. U.S. Patent 20110207749 A1, 2011.

43. Chupak, L. S.; Zheng, X.; Hu, S.; Huang, Y.; Ding, M.; Lewis, M. A.; Westphal, R. S.; Blat, Y.; McClure, A.; Gentles, R. G. Bioorg. Med. Chem. 2016, 24, 1455.

44. Bachovchin, D. A.; Koblan, L. W.; Wu, W.; Liu, Y.; Li, Y.; Zhao, P.; Woznica, I.; Shu, Y.; Lai, J. H.; Poplawski, S. E.; Kiritsy, C. P.; Healey, S. E.; DiMare, M.; Sanford, D. G.; Munford, R. S.; Bachovchin, W. W.; Golub, T. R. Nat. Chem. Biol. 2014, 10, 656 .

45. Borgstriim, B. Enzyme 1988, 308.

46. Hadváry, P.; Lengsfeld, H.; Wolfer, H. Biochem. J. 1988, 256, 357.

47. Zhi, J.; Melia, A. T.; Eggers, H.; Joly, R.; Patel, I. H. J. Clin. Pharmacol. 1995, 35, 1103.

48. Ortar, G.; Bisogno, T.; Ligresti, A.; Morera, E.; Nalli, M.; Di Marzo, V. J. Med. Chem. 2008, 51, 6970 .

49. Johnston, M.; Bhatt, S. R.; Sikka, S.; Mercier, R. W.; West, J. M.; Makriyannis, A. Gatley, S. J.; Duclos, R. I. Bioorg. Med. Chem. Lett. 2012, 22, 4585.

50. Hashimotodani, Y.; Ohno-Shosaku, T.; Tanimura, A.; Kita, Y.; Sano, Y.; Shimizu, T.; Di Marzo, V.; Kano, M. J. Physiol. 2013, 591, 4765.

51. Zhang, L.; Wang, M.; Bisogno, T.; di Marzo, V.; Alger, B. E. PLoS One 2011, 6.

52. Min, R.; Testa-Silva, G.; Heistek, T. S.; Canto, C. B.; Lodder, J. C.; Bisogno, T.; Di Marzo, V.; Brussaard, A. B.; Burnashev, N.; Mansvelder, H. D. J. Neurosci. 2010, 30,2710 .
53. Bashashati, M.; Nasser, Y.; Keenan, C. M.; Ho, W.; Piscitelli, F.; Nalli, M.; Mackie, K.; Storr, M. A.; Di Marzo, V.; Sharkey, K. A. Br. J. Pharmacol. 2015, 3099.

54. Duncan, M.; Thomas, A. D.; Cluny, N. L.; Patel, A.; Patel, K. D.; Lutz, B.; Piomelli, D.; Alexander, S. P. H.; Sharkey, K. A. Am. J. Physiol. Gastrointest. Liver Physiol. 2008, 295, G1255.

55. Bisogno, T.; Cascio, M. G.; Saha, B.; Mahadevan, A.; Urbani, P.; Minassi, A.; Appendino, G.; Saturnino, C.; Martin, B.; Razdan, R.; Di Marzo, V. Biochim. Biophys. Acta-Mol. Cell Biol. Lipids 2006, 1761, 205.

56. Bisogno, T.; Burston, J. J.; Rai, R.; Allara, M.; Saha, B.; Mahadevan, A.; Razdan, R. K.; Wiley, J. L.; Di Marzo, V. ChemMedChem 2009, 4, 946.

57. Valdeolivas, S.; Pazos, M. R.; Bisogno, T.; Piscitelli, F.; Iannotti, F. A.; Allarà, M.; Sagredo, O.; Di Marzo, V.; Fernández-Ruiz, J. Cell Death Dis. 2013, 4, e862.

58. Bisogno, T.; Mahadevan, A.; Coccurello, R.; Chang, J. W.; Allarà, M.; Chen, Y.; Giacovazzo, G.; Lichtman, A.; Cravatt, B.; Moles, A.; Di Marzo, V. Br. J. Pharmacol. 2013, 169, 784.

59. Powell, D. R.; Gay, J. P.; Wilganowski, N.; Doree, D.; Savelieva, K. V.; Lanthorn, T. H.; Read, R.; Vogel, P.; Hansen, G. M.; Brommage, R.; Ding, Z.-M.; Desai, U.; Zambrowicz, B. Front. Endocrinol. 2015, 6, 86.

60. Wilkerson, J. L.; Ghosh, S.; Bagdas, D.; Mason, B. L.; Crowe, M. S.; Hsu, K. L.; Wise, L. E.; Kinsey, S. G.; Damaj, M. I.; Cravatt, B. F.; Lichtman, A. H. Br. J. Pharmacol. 2016, 173, 1678.

61. Jenniches, I.; Ternes, S.; Albayram, O.; Otte, D. M.; Bach, K.; Bindila, L.; Michel, K.; Lutz, B.; Bilkei-Gorzo, A.; Zimmer, A. Biol. Psychiatry 2014, 1.

62. Nass, S. R.; Long, J. Z.; Schlosburg, J. E.; Cravatt, B. F.; Lichtman, A. H.; Kinsey, S. G. J. Neuroimmune Pharmacol. 2015, 364.

63. Buczynski, M. W.; Herman, M. A.; Hsu, K. L.; Natividad, L. A.; Irimia, C.; Polis, I. Y.; Pugh, H.; Chang, J. W.; Niphakis, M. J.; Cravatt, B. F.; Roberto, M.; Parsons, L. H.; Iversen, L. L. Proc. Natl. Acad. Sci. U.S.A. 2016, 113, 1086.

64. Boger, D. L.; Sato, H.; Lerner, A. E.; Hedrick, M. P.; Fecik, R. A.; Miyauchi, H.; Wilkie, G. D.; Austin, B. J.; Patricelli, M. P.; Cravatt, B. F. Proc. Natl. Acad. Sci. U.S. A. 2000, 97, 5044

65. Despres, J. P.; Golay, A.; Sjostrom, L.; Rimonabant in Obesity-Lipids Study G N. Engl. J. Med. 2005, 353, 2121.

66. Van Gaal, L. F.; Rissanen, A. M.; Scheen, A. J.; Ziegler, O.; Rössner, S.; For the RIO-Europe Study Group Lancet 2005, 19, 737.

67. Pi-Sunyer, F.; Aronne, L.; Heshmati, H.; Devin, J.; Rosenstock, J.; Group R.-N.A.S. J. Am. Med. Assoc. 2006, 295, 761.

68. Gruden, G.; Barutta, F.; Kunos, G.; Pacher, P. Br. J. Pharmacol. 2015, 173, 1116.

69. Glass, C. K.; Saijo, K.; Winner, B.; Marchetto, M. C.; Gage, H. Cell 2010, 140, 918.

70. Simmons, D. L.; Botting, R. M.; Hla, T. Pharmacol. Rev. 2004, 56, 387.

71. Nomura, D. K.; Morrison, B. E.; Blankman, J. L.; Jonathan, Z.; Kinsey, S. G.; Marcondes, M. C. G.; Ward, A. M.; Aron, H.; Conti, B.; Cravatt, B. F.; Hall, M. Science 2011, 334, 809.

72. Hernández-Torres, G.; Cipriano, M.; Hedén, E.; Björklund, E.; Canales, A.; Zian, D.; Feliú, A.; Mecha, M.; Guaza, C.; Fowler, C. J.; Ortega-Gutiérrez, S.; LópezRodríguez, M. L. Angew. Chem., Int. Ed. 2014, 53, 13765.

73. Fernandez-Suarez, D.; Celorrio, M.: Riezu-Boj, J. I.; Ugarte, A.; Pacheco, R. Gonzalez, H.; Oyarzabal, J.; Hillard, C. J.; Franco, R.; Aymerich, M. S. Neurobiol. Aging 2014, 35, 2603.

74. Schlosburg, J. E.; Blankman, J. L.; Long, J. Z.; Nomura, D. K.; Pan, B.; Kinsey, S. G.; Nguyen, P. T.; Ramesh, D.; Booker, L.; Burston, J. J.; Thomas, E. A.; Selley, D. E.; Sim-Selley, L. J.; Liu, Q.; Lichtman, A. H.; Cravatt, B. F. Nat. Neurosci. 2010, 13, 1113.

75. Viader, A.; Ogasawara, D.; Joslyn, C. M.; Sanchez-Alavez, M.; Mori, S.; Nguyen, W.; Conti, B.; Cravatt, B. F. Elife 2016, 5, 1.

76. Moreira, F. A.; Grieb, M.; Lutz, B. Best Pract. Res. Clin. Endocrinol. Metab. 2009, 23, 133.

77. Shonesy, B. C.; Bluett, R. J.; Ramikie, T. S.; Baldi, R.; Hermanson, D. J.; Kingsley, P. J.; Marnett, L. J.; Winder, D. G.; Colbran, R. J.; Patel, S. Cell Rep. 2014, 9, 1644. 